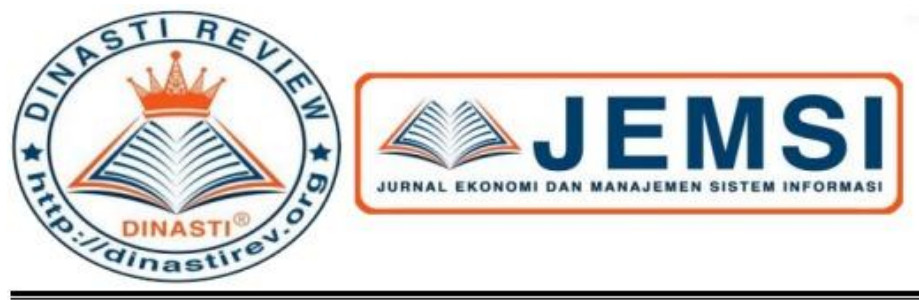

+62 878-9658-6407

087896586407 ()

https://dinastirev.org/JEMSI (-)

editor@dinastirev.org (G.

\title{
PENGARUH SELF-EFFICACY , LOCUS OF CONTROL TERHADAP KEPUASAN KERJA KARYAWAN DENGAN BUDAYA ORGANISASI SEBAGAI VARIABEL PEMODERASI PUSKESMAS AIR HAJI KABUPATEN PESISIR SELATAN
}

\section{Yeki Candra}

Universitas Putra Indonesia YPTK Padang, Indonesia

\begin{tabular}{|c|c|}
\hline $\begin{array}{l}\text { ARTICLE INFORMATION } \\
\text { Received: } 24 \text { November } 2019 \\
\text { Revised: } 30 \text { November } 2019 \\
\text { Issued: } 5 \text { Desember } 2019 \\
\text { (filled in by Editor) }\end{array}$ & $\begin{array}{l}\text { Abstrac: Department of Management, "(Effect of Self- } \\
\text { efficacy, Locus Of Control towards employee } \\
\text { satisfaction of employees with organizational culture } \\
\text { as variables moderate water clinics in South Coastal } \\
\text { district Hajj)". This research aims to test how big the } \\
\text { influence Of Self-efficacy, Locus Of Control towards } \\
\text { employee satisfaction of employees with organizational } \\
\text { culture as variables Of moderate inSouth Coastal } \\
\text { district Hajj. Samples of this study as much as } 81 \text { and } \\
\text { using the method of analysis of double linear } \\
\text { reigration, Test T, Test f and coefficient of } \\
\text { determination using SPSS } 2.1 \text { The results of research } \\
\text { obtained based on partial test (Test T) obtained: There } \\
\text { is a significant positive influence between Self-efficacy } \\
\text { (X1) to employee satisfaction. There is a positive but } \\
\text { insignificant influence of the Locus Of Control (X2) } \\
\text { against employee satisfaction. Together there is a } \\
\text { positive and significant influence between Self-efficacy, } \\
\text { Locus Of Control against employee satisfaction with } \\
\text { the organization culture as a variable of moderate in } \\
\text { the water Puskesmas Air Haji Kabupaten Pesisir } \\
\text { Selatan. } \\
\text { Keywords: Self-efficacy, Locus Of Control }\end{array}$ \\
\hline
\end{tabular}

\section{PENDAHULUAN}

Adapun Objek Puskesmas Air Haji Kecamatan Linggo Sari Baganti Kabupaten Pesisir Selatan merupakan Puskesmas yang berlokasi di Provinsi Sumatera Barat dengan alamat Jl. Raya Padang Bengkulu Koto Panai Air Haji Seperti hal nya terkait permasalahan permasalahan yang terjadi di dunia kerja dalam sebuah perusahaan. Bahwa Puskesmas Air Haji Kecamatan Linggo Sari Baganti Kabupaten Pesisir Selatan juga tidak luput dari permasalahan - permasalahan tersebut terkait akan komunikasi karyawan serta pelayanan karyawan terhadap pasien yang kurang baik dan fasilitas, seperti fasilitas alat medis untuk kesehatan, dan ruangan untuk proses rawat inap, untuk pasien juga berkurang di Puskesmas 
Air Haji Kabupaten Pesisir Selatan, adanya komplain dari pasien atau masyarakat di akibatkan oleh harapan pasien dan kepuasan suatu pelayanan fasilitas yang belum terpenuhi sehingga mengakibatkan kurangnya kepuasan pasien yang belum optimal karena kualitas pelayanan dan fasilitas yang belum maksimal.

Tabel 1.

Pencapaian Target \& Realisasi Dari Puskesmas Air Haji Kabupaten Pesisir Selatan

\begin{tabular}{l|c|c|c}
\hline \multicolumn{1}{c|}{ Indikator Kinerja } & Tahun & Target & $\begin{array}{c}\text { Realisasi Capaian } \\
\text { / Tahun }\end{array}$ \\
\hline \multicolumn{1}{c|}{$(1)$} & $(2)$ & $(3)$ & $(4)$ \\
\hline $\begin{array}{l}\text { Usia Harapan Hidup } \\
(\mathrm{UHH})\end{array}$ & 2014 & $100 \%$ & $68,4 \%$ \\
\hline $\begin{array}{l}\text { Angka kematian Ibu } \\
(\text { AKI) }\end{array}$ & 2015 & $100 \%$ & $68,9 \%$ \\
\hline $\begin{array}{l}\text { Angka kematian } \\
\text { Bayi (AKB) }\end{array}$ & 2016 & $100 \%$ & $68,9 \%$ \\
\hline $\begin{array}{l}\text { Pelayanan Kematian } \\
\text { Lansia }\end{array}$ & 2017 & $100 \%$ & $68,9 \%$ \\
\hline K4 Ibu Hamil & 2018 & $100 \%$ & $68,9 \%$ \\
\hline
\end{tabular}

Sumber: Puskesmas Air Haji Kabupaten Pesisir Selatan

Tabel diatas maka penulis tertarik melakukan penelitian pada Puskesmas Air Haji Kabupaten Pesisir Selatan yang berjudul "Pengaruh Self-efficacy, Locus Of Control Terhadap Kepuasan Kerja Karyawan Dengan Budaya Organisasi Sebagai Variabel Pemoderasi Puskesmas Air Haji Kabupaten Pesisir Selatan.

Tabel 2.

Latar Belakang Pendidikan karyawan Puskesmas Air Haji Kabupaten Pesisir Selatan

\begin{tabular}{c|c|c|c|c}
\hline \multirow{2}{*}{ NO } & \multirow{2}{*}{ Pendidikan } & \multicolumn{2}{|c|}{$\begin{array}{c}\text { Jumlah dan Status } \\
\text { Karyawan }\end{array}$} & \multirow{2}{*}{ Jumlah } \\
\cline { 3 - 4 } & & L & P & \\
\hline 1. & F-Dok & 1 & 2 & 3 \\
\hline 2. & Akper & - & 7 & 7 \\
\hline 3. & FKG & - & 1 & 1 \\
\hline 4. & SMAK & - & 1 & 1 \\
\hline 5. & SPK & - & 11 & 11 \\
\hline 6. & Akbid & - & 18 & 18 \\
\hline 7. & Pek.Kes & - & 2 & 2 \\
\hline 8. & Bidan & - & 18 & 18 \\
\hline 9. & AKL & - & 2 & 2 \\
\hline 10. & FKM & - & 2 & 2 \\
\hline 11. & AKG & - & 1 & 1 \\
\hline 12. & DII.Gizi & - & 1 & 1 \\
\hline 13. & Analis & - & 1 & 1 \\
\hline 14. & APIKES & - & 2 & 1 \\
\hline 15. & AKZI & - & 1 & 1 \\
\hline 16. & AMF & - & 1 & 1 \\
\hline 17. & A.Apoteker & - & 1 & \\
\hline
\end{tabular}




\begin{tabular}{c|c|c|c}
\hline Jumlah & 1 & 72 & 71 \\
\hline
\end{tabular}

Dari data diatas dapat kita lihat bahwa latar belakang pendidikan Puskesmas Air Haji Kabupaten Pesisir Selatan Banyak yang memiliki pendidikan akbid dan kebidanan.

Berdasarkan masalah di atas, untuk mempermudah penganalisaan dalam penelitian ini, penulis merumuskan masalah sebagai berikut::

1. Self-Efficacy Berpengaruh Terhadap Kepuasan Kerja Karyawan Pada Puskesmas Air Haji Kabupaten Pesisir Selatan?

2. Locus Of Control Berpengaruh TerhadapKepuasaan Kerja Karyawan Pada Puskesmas Air Haji Kabupaten Pesisir Selatan?

3. Self-Efficacy Berpengaruh Positif Terhadap Kepuasan Kerja Karyawan dengan Budaya Organisasi Sebagai Variabel Pemoderasi Pada Puskesmas Air Haji Kabupaten Pesisir Selatan?

4. Locus Of Control berpengaruh Positif terhadap kepuasan kerja karyawan dengan Budaya Organisasi Sebagai Variabel Pemoderasi Pada PuskesmasSeberang Padang?

\section{KAJIAN PUSTAKA}

1. Kepuasan Kerja

Lingkungan kerja yang baik, aman dan kondusif akan dapat memberi rasa Nyaman pada pegawai dalam menyelesaikan suatu tugas atau pekerjaan Lingkungan. Kerja yang menyenangkan atau sesuai dengan yang diharapkan oleh karyawan juga dapat meningkatkan semangat kerja karyawan sehingga tugas yang diberikan akan terselesaikan secara memuaskan dan tepat pada waktunya.

Menurut Handoko (2016:75) Kepuasan Kerja adalah keadaan emosional yang menyenangkan atau tidak menyenangkan bagi para karyawan memandang pekerjaan mereka. Kepuasan kerja mencerminkan perasaan seseorang terhadap pekerjaannya.

2. Self-efficacy

Self-Efficacy merupakan salah satu variabel yang diteliti oleh peneliti.Karena selfefficacy merupakan salah satu masalah yang dihadapi perusahaan.Dibawah ini dijelaskan mengenai hal hal yang mendasari pengertian self-efficacy menurut para ahli, dimensi dan indikator self-efficacy dan faktor - faktor penyebab self-efficacy. Sedangkan menurut Bandura Lau, 2015 mengungkapkan bahwa efikasi diri merupakan hasil proses kognitif sosial yang berwujud keyakinan dan pengharapan serta keputusan pada kemampuannya dalam bertindak guna memperoleh hasil yang maksimal.

3. Locus of control

Locus of controltidak bersifat statis melainkan juga dapat berubah individu yang menganut locus of control internal dapat berubah menjadi individu yang menganut locus of controleksternal, dan juga sebaliknya .

Sedangkan Menurut Jayanti, (2017:2) Locus of control menggambarkan tingkat keyakinan seseorang tentang sejauh mana mereka dapat mengendalikan faktor-faktoryang mempengaruhi keberhasilan atau kegagalan dalam dirinya.

4. Budaya Organisasi

Sebuah budaya organisasi tidak dengan sendirinya terbentuk namun, Semua itu melalui proses yang panjang yaitu menyangkut dengan berbagai interaksi yang terjadi di lingkungan organisasi tersebut. Menurut Edgar H.Shein (2014:116) Mengatakan Budaya Organisasi merupakan hasil dari interaksi antara :

a. Bias dan asumsi para pendirinya, dan

b. Apa yang dipelajari oleh para anggota pertama organisasi yang dipekerjakan oleh para pendiri, dari pengalaman mereka sendiri. 


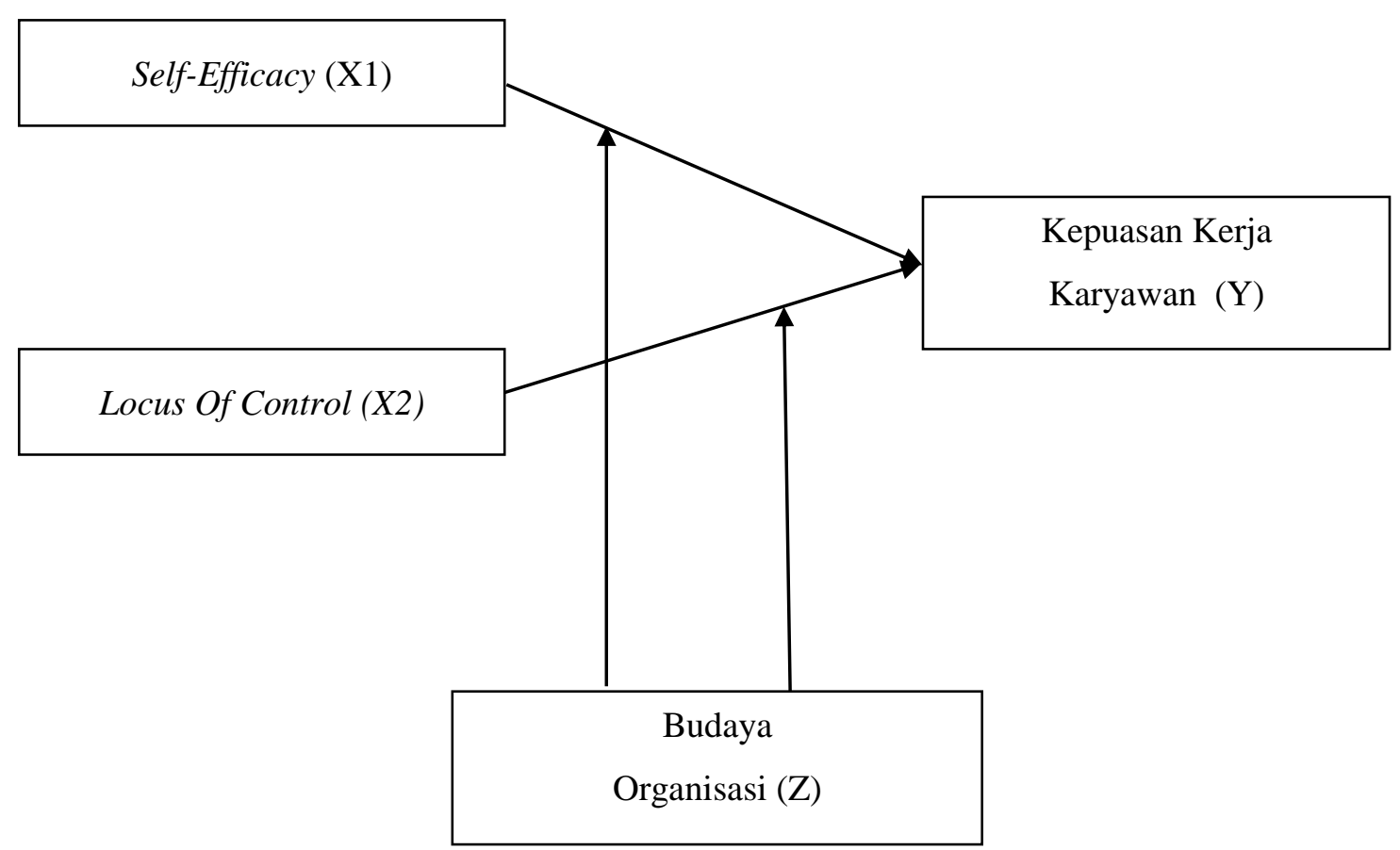

Gambar 1. Kerangaka Fikir

\section{Hipotesis}

Berdasarkan kerangka Pemikiran yang telah dikemukakan sebelumnya, maka dapat dibuat beberapa hipotesis terhadap permasalahan sebagai berikut :

H1 : Self-Efficacy berpengaruh Terhadap Kepuasan Kerja Karyawan Pada Puskesmas Air Haji Kabupaten Pesisir Selatan.

H2 : Locus Of Control berpengaruh Terhadap Kepuasan Kerja Karyawan Pada Puskesmas Air Haji Kabupaten Pesisir Selatan.

H3 : Self-Efficacy berpengaruh Terhadap Kepuasan Kerja Karyawan Dengan Budaya Organisasi Sebagai Variabel Pemoderasi Pada Puskesmas Air Haji Kabupaten Pesisir Selatan.

H4 : Locus Of Control berpengaruh Terhadap Kepuasan Kerja Karyawan Dengan Budaya Organisasi Sebagai Variabel Pemoderasi Pada Puskesmas Air Haji Kabupaten Pesisir Selatan.

\section{METODE PENELITIAN}

Data dalam penelitian ini mengunakan, Data Primer adalah sumber data yang langsung memberikan data kepada pengumpul data Sugiyono (2014:308), Data Primer dari penelitian ini mencakup data yang diperoleh dari Puskesmas Air Haji Kabupaten Pesisir Selatan, berdasarkan daftar pernyataan (kuesioner) yang terdiri dari : Variabel X Self-efficacy dan Locus Of Control dan variabel Y Kepuasan Kerja. Sedangkan Data Sekunder adalah sumber yang tidak langsung memberikan data kepada pengumpul data, misalnya lewat orang lain atau lewat dokumen sugiyono (2014:309) Sifat dari data sekunder ini adalah sebagai pendukung data primer. Data ini berupa dat Puskesmas Air Haji Kabupaten Pesisir Selatan, berkaitan dengan kepuasan kerja yang relevan digunakan sebagai pelengkap di dalam penelitian.

Menurut Riduwan (2015), analisis regresi linier berganda adalah penegmbangan dari analisis regresi sederhana. Kegunaannya yaitu untuk meramalkan nilai variabel terikat (Y) apabila variabel bebas minimal dua lebih.

Secara umum formulir dari regresi linier berganda dapat ditulis sebagai berikut :

$\mathrm{Y}=\mathrm{a}+\mathrm{b}_{1} \mathrm{X}_{1}+\mathrm{b}_{2} \mathrm{X}_{2}+\ldots \mathrm{e}$, 
dimana :

$$
\begin{aligned}
& \mathrm{Y}=\text { Kepuasan Kerja } \\
& \mathrm{a}=\text { Konstanta } \\
& \mathrm{b}=\text { koefisien korelasi } \\
& \mathrm{X} 1=\text { Self-efficacy } \\
& \mathrm{X} 2=\text { Locus } \text { Of Control } \\
& \mathrm{e}=\text { Standar eror }
\end{aligned}
$$

\section{HASIL DAN PEMBAHASAN}

Penelitian ini akan membahas tentang pengaruh self-efficacy dan locus of controlterhadap kepuasan kerja karyawan dengan budaya organisasi sebagai variabel Pemoderasi pada Puskesmas Air Haji Kabupaten Pesisir Selatan. Dalam analisis ini akan menginterprestasi data dan jawaban yang diberikan responden terhadap karakteristik responden yaitu karyawan Puskesmas Air Haji Kabupaten Pesisir Selatan.

\section{Analisis Regresi Berganda}

Analisis regresi digunakan untuk melihat pengaruh variabel independen :self-efficacy $\left(\mathrm{X}_{1}\right)$ dan

\begin{tabular}{|c|c|c|c|c|c|c|}
\hline \multicolumn{7}{|c|}{ Coefficients $^{\mathrm{a}}$} \\
\hline \multirow{2}{*}{\multicolumn{2}{|c|}{ Model }} & \multicolumn{2}{|c|}{$\begin{array}{l}\text { Unstandardized } \\
\text { Coefficients } \\
\end{array}$} & \multirow{2}{*}{$\begin{array}{l}\text { Standardized } \\
\text { Coefficients } \\
\text { Beta } \\
\end{array}$} & \multirow[t]{2}{*}{$\mathrm{t}$} & \multirow[t]{2}{*}{ Sig. } \\
\hline & & $\mathrm{B}$ & Std. Error & & & \\
\hline \multirow{4}{*}{1} & (Constant) & 2.506 & 3.215 & & .780 & .438 \\
\hline & Self & .764 & .066 & .801 & 11.652 & .000 \\
\hline & Locus & .029 & .075 & .026 & .382 & .703 \\
\hline & Budaya & .157 & .075 & .139 & 2.102 & .039 \\
\hline
\end{tabular}
locus of control $\left(\mathrm{X}_{2}\right)$ secara simultan terhadap variable dependen : kepuasan kerja karyawan $(\mathrm{Y})$ dengan budaya organisasi $(\mathrm{Z})$ sebagai variabel pemoderasi dengan asumsi variable independen lain dianggap konstan.

Tabel 3.

\section{Regresi Berganda Linier Berganda Model I}

a. Dependent Variable: Kepuasan

Sumber : Data Primer (diolah) SPSS 23

Berdasarkan tabel diatas maka dapat dilihat persamaan regresinya yaitu :

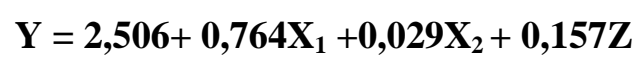

Dari persamaan regresi berganda di atas dapat disimpulkan bahwa :

1. Nilai konstanta sebesar 2,506; artinya jika self-efficacy $\left(\mathrm{X}_{1}\right)$, locus of control $\left(\mathrm{X}_{2}\right)$ dan budaya organisasi(Z) konstan (tetap), maka nilai variabel kepuasan kerja karyawan (Y) nilainya adalah sebesar 2,506.

2. Koefisien regresi variabelself-efficacy $\left(\mathrm{X}_{1}\right)$ sebesar 0,764 ; jika variabel self-efficacy $\left(\mathrm{X}_{1}\right)$ mengalami peningkatan satu (1) satuan bobot dengan asumsi variabel locus of control $\left(\mathrm{X}_{2}\right)$ dan budaya organisasi(Z) bernilai konstan (tetap) maka nilai variabel kepuasan kerja karyawan (Y) akan mengalami peningkatan sebesar 0,764 .

3. Koefisien regresi variabel locus of control $\left(\mathrm{X}_{2}\right)$ sebesar 0,029 ; jika locus of control $\left(\mathrm{X}_{2}\right)$ mengalami peningkatan satu (1) satuan bobot dengan asumsi variabel self-efficacy $\left(\mathrm{X}_{1}\right)$ dan budaya organisasi(Z) bernilai konstan (tetap) maka variabel kepuasan kerja karyawan (Y) akan mengalami peningkatan sebesar 0,029 . 
4. Koefisien regresi variabel budaya organisasi(Z) sebesar 0,157 ; jika variabel budaya organisasi(Z) mengalami peningkatan satu (1) satuan bobot dengan asumsi variabel self-efficacy $\left(\mathrm{X}_{1}\right)$ dan locus of control $\left(\mathrm{X}_{2}\right)$ diabaikan (0) maka nilai variabel kepuasan kerja karyawan (Y) akan mengalami peningkatan sebesar 0,157 .

Tabel 4.

Regresi Berganda Linier Berganda Model II

\begin{tabular}{|c|c|c|c|c|c|c|}
\hline \multicolumn{7}{|c|}{ Coefficients $^{\mathrm{a}}$} \\
\hline \multirow{2}{*}{\multicolumn{2}{|c|}{ Model }} & \multicolumn{2}{|c|}{$\begin{array}{l}\text { Unstandardized } \\
\text { Coefficients }\end{array}$} & \multirow{2}{*}{$\begin{array}{l}\text { Standardized } \\
\text { Coefficients } \\
\text { Beta }\end{array}$} & \multirow[t]{2}{*}{$\mathrm{t}$} & \multirow[t]{2}{*}{ Sig. } \\
\hline & & B & Std. Error & & & \\
\hline \multirow{3}{*}{1} & (Constant) & 19.478 & 1.876 & & 10.381 & .000 \\
\hline & X1_Z & .025 & .003 & .873 & 7.970 & .000 \\
\hline & $\mathrm{X} 2 \_\mathrm{Z}$ & -.010 & .003 & -.320 & -2.921 & .005 \\
\hline
\end{tabular}

a. Dependent Variable: Kepuasan

Sumber : Data Primer (diolah) SPSS 23

Berdasarkan tabel diatas maka dapat dilihat persamaan regresinya yaitu :

$$
\mathrm{Y}=19,478+0,025\left[\mathrm{X}_{1} * \mathrm{Z}\right]-\mathbf{- 0 , 0 1 0}\left[\mathrm{X}_{2} * \mathrm{Z}\right]
$$

Dari persamaan regresi berganda di atas dapat disimpulkan bahwa :

1. Nilai konstanta sebesar 19,478; artinya jika moderasi $\left.\mathrm{I}_{\left[\mathrm{X}_{1}\right.} * \mathrm{Z}\right]$ dan moderasi II $\left[\mathrm{X}_{2} * \mathrm{Z}\right]$ konstan (tetap), maka nilai variabel kepuasan kerja karyawan (Y) nilainya adalah sebesar 19,478 .

2. Koefisien regresi variabel moderasi $\mathrm{I}\left[\mathrm{X}_{1} * \mathrm{Z}\right]$ sebesar 0,025 ; jika variabel moderasi I $\left[\mathrm{X}_{1} * \mathrm{Z}\right]$ mengalami peningkatan satu (1) satuan bobot dengan asumsi variabel moderasi II $\left[\mathrm{X}_{2} * \mathrm{Z}\right]$ bernilai konstan (tetap) maka nilai variabel kepuasan kerja karyawan (Y) akan mengalami peningkatan sebesar 0,025.

3. Koefisien regresi variabel moderasi II $\left[\mathrm{X}_{2} * \mathrm{Z}\right]$ sebesar $-0,010$; jika moderasi II $\left[\mathrm{X}_{2} * \mathrm{Z}\right]$ mengalami peningkatan satu (1) satuan bobot dengan asumsi variabel moderasi $I$ [ $\left.\mathrm{X}_{1} * \mathrm{Z}\right]$ bernilai konstan (tetap) maka variabel kepuasan kerja karyawan (Y) akan mengalami penurunan sebesar 0,010 .

\section{Hipotesa Secara Parsial (Uji t)}

Uji t dimaksud untuk menguji signifikan pengaruh variabel bebas dan terikat secara parsial. Dimana pengujian ini membandingkan antara probabilitas signifikan dengan alpha 0,05 dengan derajat kebebasan $(\mathrm{df})=\mathrm{n}-\mathrm{k}-1$ yaitu 81-2-1=78( $\mathrm{n}$ adalah jumlah responden dan $\mathrm{k}$ adalah jumlah variabel independent) sehingga hasil yang diperoleh untuk ttabel sebesar 1,990 .

Dari hasil pengujian ini probabilitas signifikan lebih kecil daripada alpha 0,05 maka diperoleh Ho ditolak dan Ha diterima, berarti ada hubungan dan bila probabilitas signifikas lebih besar dari pada alpha 0,05 maka diperoleh Ho diterima dan Ha ditolak.

Dari pengujian pada variabel self-efficacy $\left(\mathrm{X}_{1}\right)$ dan locus of control $\left(\mathrm{X}_{2}\right)$ terhadap kepuasan kerja karyawab (Y) dengan budaya organisasi (Z) sebagai variabel pemoderasiterlihat pada table 4.20 dan 4.21 diatas: 
1. Pengaruh Self-Efficacy Terhadap Kepuasan Kerja Karyawan

Dari tabel diatas di ketahui $\mathrm{t}$ hitung $>\mathrm{t}$ tabel $(16,652>1,990)$ dengan tingkat siginifikan $(0,000<0,05)$, artinya secara parsial terdapat pengaruh positif dan signifikan antara selfefficacy terhadap kepuasan kerja karyawan. Dengan demikian Ho ditolak dan Ha diterima.

2. Pengaruh Locus of ControlTerhadap Kepuasan Kerja Karyawan

Dari tabel diatas di ketahui $t$ hitung $<\mathrm{t}$ tabel $(0,382>1,990)$ dengan tingkat siginifikan $(0,703<0,05)$, artinya secara parsial terdapat tidak pengaruh positif dan signifikan antara locus of control terhadap kepuasan kerja karyawan. Dengan demikian Ho diterima dan Ha ditolak.

3. Pengaruh Self-Efficacy Terhadap Kepuasan Kerja Karyawan dengan Budaya Organisasi sebagai Variabel Pemoderasi

Dari tabel diatas di ketahui t hitung $>t$ tabel $(7,970>1,990)$ dengan tingkat siginifikan $(0,000<0,05)$, artinya secara parsial terdapat pengaruh positif dan signifikan antara interaksi variabel self-efficacy dengan variabel budaya organisasi terhadap kepuasan kerja karyawan, artinya budaya organisasi mampu memperkuat pengaruh self-efficacy terhadap kepuasan kerja karyawan. Dengan demikian Ho ditolak dan Ha diterima.

4. Pengaruh Locus of Control Terhadap Kepuasan Kerja Karyawan dengan Budaya Organisasi sebagai Variabel Pemoderasi

Dari tabel diatas di ketahui $t$ hitung <t tabel $(-2,921<1,990)$ dengan tingkat siginifikan $(0,005<0,05)$, artinya secara parsial terdapat pengaruh negatif dan signifikan antara interaksi variabel locus of control dengan variabel budaya organisasi terhadap kepuasan kerja karyawan, artinya budaya organisasi memperlemah pengaruh locus of control terhadap kepuasan kerja karyawan. Dengan demikian Ho ditolak dan Ha diterima.

\section{Uji Hipotesis Secara Simultan (Uji F)}

Uji $\mathrm{F}$ dimaksudkan untuk menguji hipotesis keempat dalam penelitian ini yang menyatakan bahwa variabel self-efficacy $\left(\mathrm{X}_{1}\right)$ dan locus of control $\left(\mathrm{X}_{2}\right)$ berpengaruh positif signifikan terhadap kepuasan kerja karyawan (Y) dengan buadaya organisasi (Z) sebagai variabel pemoderasi. Uji F menggunakan taraf signifikan 0,05 (uji 2sisi) untuk nilai Ftabel menggunakan tingkat keyakinan 95\%, alpha 5\% (jumlah variabel-1) atau 3-1=2 (n-k-1) atau 81-2-1=78, maka hasil untuk Ftabel adalah 3,113.

\section{Tabel 5.}

Pengujian Hipotesis Semua Variabel Secara Simultan Model I ANOVA $^{\mathrm{a}}$

\begin{tabular}{|c|c|c|c|c|c|c|}
\hline Model & & $\begin{array}{|ll|}\text { Sum } & \text { of } \\
\text { Squares } & \\
\end{array}$ & df & Mean Square & $\mathrm{F}$ & Sig. \\
\hline 1 & $\begin{array}{l}\text { Regression } \\
\text { Residual } \\
\text { Total }\end{array}$ & \begin{tabular}{|l|}
622.183 \\
307.471 \\
929.654 \\
\end{tabular} & $\begin{array}{l}3 \\
77 \\
80\end{array}$ & $\begin{array}{l}207.394 \\
3.993\end{array}$ & 51.938 & $.000^{\mathrm{b}}$ \\
\hline
\end{tabular}

a. Dependent Variable: Kepuasan

b. Predictors: (Constant), Budaya, Self, Locus

Sumber : Data Primer (diolah) SPSS 24

Berdasarkan tabel diatas didapatkan sig yaitu $0,000<0,05$ angka ini menunjukkan $\mathrm{F}_{\text {hitung }} 51,938>\mathrm{F}_{\text {tabel }}$ 3,113 maka penulis berkesimpulan self-efficacy $\left(\mathrm{X}_{1}\right)$, locus of control $\left(\mathrm{X}_{2}\right)$ dan budaya organisasi(Z)mempunyai pengaruh yang berarti atau signifikan terhadap kepuasan kerja karyawan (Y). Maka dapat disimpulkan bahwa Ho ditolak dan Ha diterima. 
Tabel 5.

ANOVA $^{\text {a }}$

Pengujian Hipotesis Semua Variabel Secara Simultan Model II

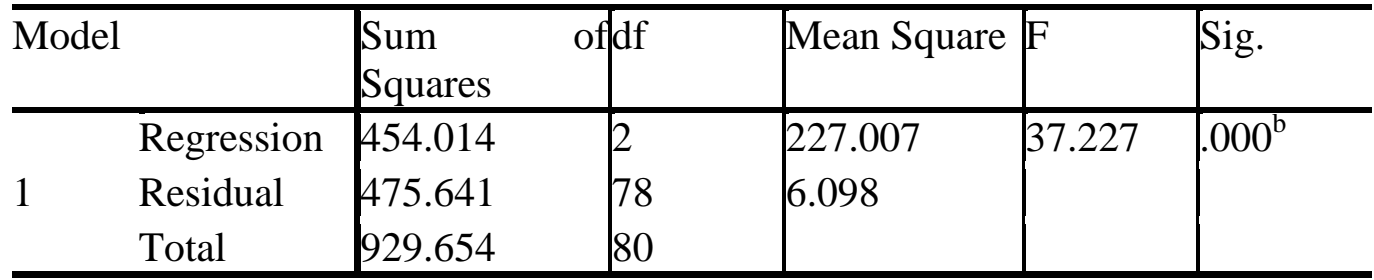

a. Dependent Variable: Kepuasan

b. Predictors: (Constant), X2_Z, X1_Z

Sumber : Data Primer (diolah) SPSS 24

Berdasarkan tabel diatas didapatkan sig yaitu $0,000<0,05$ angka ini menunjukkan $\mathrm{F}_{\text {hitung }} 37,227>\mathrm{F}_{\text {tabel }}$ 3,113 maka penulis berkesimpulan moderasi I [ $\mathrm{X}_{1} * \mathrm{Z}$ ] dan moderasi II $\left[\mathrm{X}_{2} * \mathrm{Z}\right]$ mempunyai pengaruh yang berarti atau signifikan terhadap kepuasan kerja karyawan (Y). Maka dapat disimpulkan bahwa Ho ditolak dan Ha diterima.

\section{Koefisien Determinasi $\left(\mathbf{R}^{2}\right)$}

Analisa koefisien determinasi dalam regresi linear berganda digunakan untuk mengetahui persentase sumbangan pengaruh variabel independen yang terdiri dari selfefficacy $\left(\mathrm{X}_{1}\right)$, locus of control $\left(\mathrm{X}_{2}\right)$ dan budaya organisasi(Z)secara simultan terhadap kepuasan kerja karyawan (Y).

Table 6.

Hasil Uji Koefisien Determinasi Model I

Model Summary

\begin{tabular}{l|l|l|l|l}
\hline Model & R & R Square & $\begin{array}{l}\text { Adjusted R } \\
\text { Square }\end{array}$ & $\begin{array}{l}\text { Std. Error of } \\
\text { the Estimate }\end{array}$ \\
\hline 1 & $.818^{\mathrm{a}}$ & .669 & .659 & 1.998 \\
\hline
\end{tabular}

a. Predictors: (Constant), Budaya, Self, Locus

Sumber : Data Primer (diolah) SPSS 24

Berdasarkan tabel di atas diperoleh angkaAdjuested $\mathrm{R}^{2}$ ( $\mathrm{R}$ square) sebesar 0,659atau $65,9 \%$, hal ini menunjukkan bahwa persentase sumbangan variabel self-efficacy $\left(\mathrm{X}_{1}\right)$, locus of control $\left(\mathrm{X}_{2}\right)$ dan budaya organisasi(Z)terhadap variabel dependen kepuasan kerja karyawan (Y) sebesar 0,659 atau 65,9\%. Sedangkan sisanya sebesar 34,4\% dipengaruhi oleh variabel lain di luar penelitian ini.

Table 7.

Hasil Uji Koefisien Determinasi Model II

Model Summary

\begin{tabular}{l|l|l|l|l}
\hline Model & $\mathrm{R}$ & R Square & $\begin{array}{l}\text { Adjusted } \\
\text { Square }\end{array}$ & $\begin{array}{l}\mathrm{R} \\
\text { Std. Error of } \\
\text { the Estimate }\end{array}$ \\
\hline 1 & $.699^{\mathrm{a}}$ & .488 & .475 & 2.469 \\
\hline
\end{tabular}

a. Predictors: (Constant), X2_Z, X1_Z

Sumber : Data Primer (diolah) SPSS 24 
Berdasarkan tabel di atas diperoleh angkaR ${ }^{2}$ ( $\mathrm{R}$ square) sebesar 0,475 atau $47,5 \%$, hal ini menunjukkan bahwa persentase sumbangan variabel interasi variabel self-efficacy dengan budaya organisasi $\left[\mathrm{X}_{1} * \mathrm{Z}\right]$ dan variabel interaksi locus of control dengan budaya organisasi $\left[\mathrm{X}_{2} * \mathrm{Z}\right]$ terhadap variabel dependen kepuasan kerja karyawan (Y) sebesar 0,475 atau $47,5 \%$. Sedangkan sisanya sebesar $52,5 \%$ dipengaruhi oleh variabel lain di luar penelitian ini.

\section{Interpertasi Hasil Penelitian}

Berdasarkan analisis dan pembahasan diatas, maka hasil penelitian tersebut dapat diinterpretasikan hal - hal sebagai berikut:

1. Terdapat pengaruh self-efficacyterhadap kepuasan kerja karyawan

Berdasarkan penelitian yang dilakukan self-efficacysecara parsial berpengaruh positif signifikan terhadap kepuasan kerja karyawan, dimana dapat dilihat di tabel 4.20 yang menunjukan nilai signifikan 0,000dibawah (lebih kecil) dari 0,05. $\boldsymbol{H}_{\mathbf{1}}$ diterima yang berarti dapat disimpulkan self-efficacyberpengaruh positif signifikan terhadap kepuasan kerja karyawanpadaPuskesmas Air Haji Kabupaten Pesisir Selatan. Semakin tinggi self-efficacy karyawan, maka semakin tinggitingkat kepuasan kerja karyawan. Hasil penelitian ini selajan dengan penelitian Amanah,dkk (2016) yang juga menemukan bahwa selfefficacyberpengaruh signifikan terhadap kepuasan kerja karyawan.

2. Tidak terdapat pengaruh locus of controlterhadap kepuasan kerja karyawan

Berdasarkan penelitian yang dilakukan locus of controlsecara parsial tidak berpengaruh positif signifikan terhadap kepuasan kerja karyawan, dimana dapat dilihat di tabel 4.20 yang menunjukan nilai signifikan 0,703diatas (lebih besar) dari $0,05 . \boldsymbol{H}_{\mathbf{2}}$ ditolakyang berarti dapat disimpulkan locus of controlberpengaruh positif signifikan terhadap kepuasan kerja karyawan pada Puskesmas Air Haji Kabupaten Pesisir Selatan. baik atau buruknya karyawan dalam mengontrol diri mereka atas keinginan mereka, tidak akan meningkatkan atau menurunkan tingkat kepuasan kerja karyawan. Hasil penelitian ini sejalan dengan penelitian yang dilakukan oleh Amanah,dkk (2016) yang juga menemukan bahwa locus of controlberpengaruh signifikan terhadap kepuasan kerja karyawan.

3. Terdapat pengaruh self-efficacyterhadap kepuasan kerja karyawan dengan budaya organisasi sebagai variabel pemoderasi

Berdasarkan penelitian yang dilakukan interaksi variabel self-efficacy dengan budaya organisasi secara parsial berpengaruh positif signifikan terhadap kepuasan kerja karyawan, dimana dapat dilihat di tabel 4.21 yang menunjukan nilai signifikan 0,000 dibawah(lebih kecil) dari $0,05 . \boldsymbol{H}_{\mathbf{3}}$ diterima yang berarti dapat disimpulkan budaya organisasi mampu memperkuat pengaruh self-efficacy terhadap kepuasan kerja karyawan padaPuskesmas Air Haji Kabupaten Pesisir Selatan.

4. Terdapat pengaruh locus of control terhadap kepuasan kerja karyawan dengan budaya organisasi sebagai variabel pemoderasi

Berdasarkan penelitian yang dilakukan interaksi variabel locus of control dengan budaya organisasi secara parsial berpengaruh positif signifikan terhadap kepuasan kerja karyawan, dimana dapat dilihat di tabel 4.21 yang menunjukan nilai signifikan 0,005 dibawah(lebih kecil) dari 0,05. $\boldsymbol{H}_{\mathbf{4}}$ diterima yang berarti dapat disimpulkan budaya organisasi memperlemah pengaruh locus of control terhadap kepuasan kerja karyawan padaPuskesmas Air Haji Kabupaten Pesisir Selatan. 


\section{KESIMPULAN DAN SARAN}

\section{Kesimpulan}

Berdasarkan hasil penelitia tentang pengaruh self-efficacydanlocus of control terhadapkepuasan kerja karyawan dengan budaya organisasi sebagai variabel pemoderasi pada Puskesmas Air Haji Kabupaten Pesisir Selatan, maka dapat disumpulkan sebagai berikut:

1. Terdapat pengaruh yang signifikan antara self-efficacy secara parsial terhadap kepuasan kerja karyawan Puskesmas Air Haji Kabupaten Pesisir Selatan, hal ini dapat di ketahui dari $\mathrm{t}$ hitung $>\mathrm{t}$ tabel $(16,652>1,990)$ dengan tingkat siginifikan $(0,000<0,05)$. Dengan demikian Ho ditolak dan Ha diterima.

2. Tidak terdapat pengaruh yang signifikan antara locus of control secara parsial terhadap kepuasan kerja karyawan Puskesmas Air Haji Kabupaten Pesisir Selatan, hal ini dapat di ketahui dari $\mathrm{t}$ hitung $<\mathrm{t}$ tabel $(0,382>1,990)$ dengan tingkat siginifikan $(0,703<0,05)$. Dengan demikian Ho diterima dan Ha ditolak.

3. Terdapat pengaruh yang signifikan antara self-efficacy secara parsial terhadap kepuasan kerja karyawan, hal ini dapat di ketahui dari ketahui $t$ hitung $>t$ tabel $(7,970>1,990)$ dengan tingkat siginifikan $(0,000<0,05)$, artinya secara parsial terdapat pengaruh positif dan signifikan antara interaksi variabel self-efficacy dengan variabel budaya organisasi terhadap kepuasan kerja karyawan Puskesmas Air Haji Kabupaten Pesisir Selatan, artinya budaya organisasi

4. mampu memperkuat pengaruh self-efficacy terhadap kepuasan kerja karyawan. Dengan demikian Ho ditolak dan Ha diterima..

5. Terdapat pengaruh yang signifikan antara locus of control secara parsial terhadap kepuasan kerja karyawan, hal ini dapat di ketahui dari thitung <t tabel $(-2,921<1,990)$ dengan tingkat siginifikan $(0,005<0,05)$, artinya secara parsial terdapat pengaruh positif dan signifikan antara interaksi variabel locus of control dengan variabel budaya organisasi terhadap kepuasan kerja karyawan Puskesmas Air Haji Kabupaten Pesisir Selatan, artinya budaya organisasi memperlemah pengaruh locus of control terhadap kepuasan kerja karyawan. Dengan demikian Ho ditolak dan Ha diterima.

\section{Saran}

Berdasarkan hasil penelitian yang telah dilakukan, ada beberapa saran yang dapat dipertimbangkan oleh beberapa pihak:

1. Bagi perusahaan

a. Diharapkan pihak manajemen Puskesmas Air Haji Kabupaten Pesisir Selatan sebaiknya memberikan jaminan kesahatan, memberikan pengawasan dan mekanisme bonus yang memadai, sehingga karyawan mampu berkontribusi besar kepada perusahaan

b. Diharapkan perusahaan menjali hubungan yang baik dengan karyawan, sehingga karyawan dapat megembangkan kemampuan dirinya, yang juga akan berdampak baik bagi perusahaan.

2. Bagi karyawan

a. Karyawan diharapkan mampu bekerja dengan baik, sehingga menghasilankan kinerja yang tinggi yang juga akan berdampak terhadap perusahaan.

b. Karyawan diharapkan mampu memenuhi target kerja yang telah ditetapkan oleh perusahaan, menyelesaikan pekerjaan tepat waktu serta berkontribusi terhadap kemajuan perusahaan. 
3. Bagi peneliti selanjutnya

a. Bagi penelitian selanjutnya untuk melakukan penelitian sebaiknya mengambil sampel dari keseluruhan karyawan perusahaan agar dapat diperoleh hasil yang lebih baik. Serta penelitian selanjutnya harus dapat mengembangkan penelitian ini dengan menambahkan variabel lain seperti financial attitude, literasi keuangan dan variabel lainya yang mungkin berpengaruh terhadap kepuasan kerja karyawan.

b. Penelitian selanjutnya diharapkan memperluas objek penelitian, tidak hanya pada Puskesmas Air Haji Kabupaten Pesisir Selatan, tetapi juga pada industri lainya maupun instansi pemerintahan sehingga permasalahan dapat di generalisir.

\section{DAFTAR RUJUKAN}

Baron dan Byne Gufron dan rinaswita, (2016) Self efficacy Sebagai Evaluasi Seseorang Mengenai Kemampuan atau kompetisi diri.

Bandura, (2014). self-efficacy, locus of control terhadap kepuasan kerja dan kepercayaan individu.

Bandura Lunengburg, (2015) self-efficacy, locus of control, Terhadap pengorganisasian

Birgid dan Gernot, (2014) Kepuasan kerja dengan self-efficacy dalam hubungan positif dan signifikan

Edwin B. Flippo(2015:23) dalam Danang adalah perencanaan, pengorganisasian, pengarahan, dan organisasi.

Fred, C. Lunenburg, (2015)past performance, vicarious experience, verbal persuasion, emotional cues.

Ferial, (2016 : 1:310) Locus of control terhadap kompetensi yang dimiliki individu

Handoko ,(2016:75) Kepuasan kerja adalah keadaan emosional yang menyenangkan bagi para karyawan.

Hasibuan ,2016:206) Kepuasan dan fungsi dalam individu dan indikator dalam kepuasan kerja.

Hartiningtyas, (2016 :1129) karakteristik piskologi sebagai keyakinan masing-masing individu.

Judge dan Bono, (2015) Self-efficacy mempunyai keyakinan dalam mengerjakan tugas dengan baik.

Jewel,(2014) Kepuasan kerja berkaitan dengan individu atas kemampuan yang dimilikinya

Jayanti ,(2017:02) Locus Of Control dan tingkat keyakinan dapat mengendalikan faktorfaktor mempengaruhi penghasilan.

Kretner dan Kinicki ,(2015:175) Kepuasan kerja mempengaruhi pemenuhan kebutuhan dan pencapaian nilai.

Liza, (2014) Self-efficacy mempresentasikan penelitian tingkatan, kekuatan keadaan umum.

Marliani,( 2015: 244 ) Kepuasan kerja dan sikap positif yang meliputi perasaan dan tingkah laku terhadap pekerjaan.

Muah, (2017 : 03) Locus of control tanggung jawab terhadap kegiatan dalam kontrol atau diluar control

Moma, La (2014). Peningkatan self-efficacy matematis siswa SMP melalui Pembelajaran generatife. Cakrawala Pendidikan, 3, 434-444.

Marihot Tua E.H. dalam Danang (2015:1) manajemen sumber daya manusia : "Human resources management isthe activities undertaken to attract, develop, motivate and maintain a highperforming workforce within the organizatin"

Prasetya (2016) Self-eficacy yang tinggi untuk mencapai suatu kinerja yang baik.

Rizal dkk, (2015)self-efficacy dan locus of control terhadap kepuasan kerja karyawan.

Sarita dan agustia (2014) locus of control dengan kepuasan kerja karyawan dan pengorganisasian. 
Sopiah (2017:170) jobsatifation ia a pleasurable oremotional state resulting from the appraisal of one's or job expreince.

Sanjiwani dan Wisadha, (2016:928)locus of control, locus of control internal dan locus of control eksternal terhadap Motivasi dan Kepuasan kerja Karyawan.

Sapariyah ,2015. Pengaruh Self-esteem, self-efficacy Terhadap kinerja karyawan.

Sugiyono,(2015) Metode penelitian kuantitatif kualitatif dan R\&D Yogyakarta: CAPS

Suprayogi, (2017 :133) Locus of control dapat mengetahui peristiwa dalam hidup.

Sekaran, (2014) ,Research Method for Business, Meetodologi Penelitian Untuk Bisnis. Jakarta

Yakin dan erdil (2014 ).self-efficacy, locus of control terhadap kepuasan kerja karyawan. 